\title{
Volume Management and Resuscitation in Trauma
}

\author{
Matthew J. Bradley $\cdot$ Vincente S. Nelson
}

Published online: 2 September 2014

(C) Springer Science+Business Media New York (outside the USA) 2014

\begin{abstract}
Trauma remains an enormous burden on the American medical system. While patients of all ages sustain severe trauma, it remains the most common cause of death in young adults. Exsanguination from uncontrolled hemorrhage is the leading cause of preventable death among the traumatically injured. The lethal triad of trauma is a culmination of coagulopathy, acidosis, and hypothermia that can rapidly deteriorate and lead to a patient's demise if not treated accordingly. The goal of trauma resuscitation is to prevent or halt this triad while minimizing iatrogenic injury. The provider has many options available in his armamentarium for resuscitation, but each carries its own risks and benefits. Over the past two decades, trauma research has given us a better understanding of and improved management strategies for this triad. This chapter will explore the various resuscitative options available and summarize the most recent literature regarding their use.
\end{abstract}

Keywords Trauma - Damage control laparotomy · Damage control resuscitation - Massive transfusion

M. J. Bradley $(\bowtie)$

Naval Medical Research Center, Bethesda, 503 Robert Grant Avenue, Silver Spring, MD 20910, USA

e-mail: matthew.bradley@med.navy.mil; mjbrad7@yahoo.com

M. J. Bradley · V. S. Nelson

Walter Reed National Military Medical Center, 4625 N Chelsea

Ln, Bethesda, MD 20814, USA

e-mail: nelsn9999@gmail.com

\section{Introduction}

Exsanguination from uncontrolled hemorrhage is responsible for nearly $40 \%$ of all trauma deaths [1]. Despite numerous advancements in medical infrastructure and technology, it remains the leading cause of preventable death in this population [2,3]. Multiple factors contribute to ongoing hemorrhage, thereby increasing the odds of a poor outcome. The time passed before definitive care significantly increases the risk of developing hypothermia, a factor which independently increases mortality [4, 5]. However, hypothermia is not the only mechanism at work; other intrinsic processes are at play [6]. Hyperfibrinolysis, platelet dysfunction, and hypoperfusion have all been implicated as contributors to this "coagulopathy of trauma", which has been shown to increase coagulation times, and most importantly, mortality in this population [3, 7-10]. From the very beginning, trauma resuscitation has been an evolving science, a science very different than elective surgery, focused on minimizing and preventing the complications from coagulopathy, acidosis, and hypothermia. The goal of resuscitation, therefore, is to address these problems while minimizing additional insults that can spiral out of control in the hemorrhaging patient. This chapter is a comprehensive review of the literature regarding the numerous resuscitative options currently available, as well as, recommendations for resuscitation of the trauma patient.

Crystalloids

The 9th edition of the Advanced Trauma Life Support (ATLS) recommends giving up to $2 \mathrm{~L}$ of warm isotonic crystalloid as the initial resuscitative agent [11]. This recommendation is to help maintain perfusion pressure in the 
hypotensive trauma patient especially in centers that do not have rapid access to stored blood products. Infusing higher volumes of crystalloids is not without its complications, although, limiting crystalloid infusion is a practice often easier said than done. Complications from excessive crystalloid resuscitation such as pulmonary edema is welldocumented, however, evolving evidence has demonstrated that this practice's impact extends beyond the lungs [12].

The widespread acceptance and employment of damage control laparotomy (DCL) in the treatment of devastating abdominal injuries has revolutionized the care of the severely injured trauma patient. First described in 1993, the tenants of DCL include surgical control of hemorrhage and contamination, deferment of definitive repair until physiologically stable, and temporary abdominal closure [13]. This approach has since been augmented by incorporating damage control resuscitation (DCR) principles, which aim to reverse coagulopathy through the utilization of permissive hypotension, judicious use of isotonic crystalloids, and a balanced approach to blood transfusion [14]. The theoretical objective behind permissive hypotension is to maintain adequate perfusion to vital organs without raising the blood pressure to such a level that clots dislodge, perpetuating further bleeding. The United States military was one of the first to incorporate these objectives into policy, and documented a segmental decrease in mortality among patients who received a massive transfusion each year following its adoption [15]. Many civilian trauma centers have adopted this policy, with subsequent improvement in both transfusion volumes as well as overall mortality [16]. Although promising, no randomized controlled trials have been performed to validate these findings.

Recent studies have investigated the morbidity associated with aggressive fluid resuscitation following DCL including the development of abdominal compartment syndrome and anastomotic leaks following colon resection $[17,18]$. One group found the amount of crystalloid infused in the first $24 \mathrm{~h}$ to be an independent risk factor for failure of primary facial closure [19]. As the rate of complications, particularly enteroatmospheric fistulas, is directly proportional to the length of time the abdomen is left open, cautious crystalloid use is advocated [20]. The use of $3 \%$ hypertonic normal saline (HTS) represents one potential solution to limiting the amount of crystalloid administration. One group found reliance on HTS as the sole maintenance fluid following DCL was not only associated with significantly less IVF during the first three postoperative days, but it also permitted surgeons to close the abdomen $100 \%$ of the time compared to a $76 \%$ closure rate in those receiving isotonic fluids [21]. Surprisingly renal function was not significantly affected with this approach, a finding that may be related to hypertonic saline's ability to blunt the inflammatory response [22]. These findings raise the question as to whether hypertonic saline has a defining role in trauma resuscitation outside of its use in the care of patients with traumatic brain injuries (TBIs) [23].

Given the plethora of complications associated with over-resuscitation, several groups have sought to determine whether an even more conservative approach should be taken. In a prospective randomized manner, one group compared a target systolic blood pressure (SBP) of $70 \mathrm{mmHg}$ with $90 \mathrm{mmHg}$, a standard resuscitation goal [24]. The authors found that a lower SBP goal significantly reduced transfusion requirements without a concomitant increase in mortality. They concluded that this resuscitative threshold was a safe and viable goal. A second group found similar results when comparing the accepted MAP of $>65 \mathrm{mmHg}$ to resuscitation to a MAP of only $50 \mathrm{mmHg}$ [25]. The groups' findings add further support to the concept of permissive hypotension.

Complicating the resuscitation strategy of permissive hypotension is hemorrhage in the setting of a concurrent TBI. Several investigators have documented that even a single episode of hypotension, defined as SBP $<$ $90 \mathrm{mmHg}$, in severe TBI is associated with a substantial increase in morbidity and mortality $[26,27]$. Therefore, in this instance it is recommended to maintain a SBP > $90 \mathrm{mmHg}$ to minimize secondary brain insult. In those TBI patients with intracranial pressure monitors, therapy should also include sustaining a cerebral perfusion pressure (CPP) around $60 \mathrm{mmHg}$ [28]. Although the exact CPP to target is not known critical brain ischemia has been shown to occur in the $50-60 \mathrm{mmHg}$ range [29]. Likewise, aggressively raising the CPP threshold above $70 \mathrm{mmHg}$, in an attempt to prevent cerebral desaturation, with volume expansion and vasopressors has been associated with deleterious effects, such as ARDS, and should be avoided [30, 31].

\section{Colloids}

In no area of resuscitation does the provider have so many different options than in colloids. Hydroxyethyl starch, albumin, and dextran solutions, available in varying concentrations, are vital components of the physician's armamentarium. What makes these solutions invaluable is their ability to remain intravascular and expand the total blood volume to varying degrees [32].

A significant amount of research has focused on the use of $6 \%$ hetastarch as a primary resuscitative agent in trauma patients. Derived from plants, the fluid bypasses the theoretical harm of infection inherent to human-derived solutions such as albumin and blood products [33]. Its smaller volume, and therefore reduced weight, makes it an attractive option for use in the pre-hospital setting and for 
military first responders. Results of clinical trials thus far have been conflicting, with some groups touting decreased mortality as compared to a resuscitative strategy based on crystalloids [34, 35], while others have identified severalfold increases in both morbidity, particularly acute kidney injury, and overall mortality $[33,36]$. The higher incidence of end-organ injury demonstrated with colloids has been postulated to be a result of a pro-inflammatory state induced by the fluid [22].

Albumin is a colloid derived from human plasma. It is available in varying concentrations from 5 to $25 \%$. There have been multiple small randomized controlled trials that compared $20 \%$ albumin to hydroxyethyl starch in the treatment of moderate-to-severely injured trauma patients [37]. The majority found albumin to be inferior to the synthetic colloid, particularly with respect to improvements in cardiac index, decreased vasopressor use, and higher $\mathrm{PaO}_{2} / \mathrm{FiO}_{2}$ ratios [38-40].

Two Cochran Review analyses could not find evidence to conclude that colloid was superior to crystalloids in the treatment of critically ill patients [41, 42]. The Saline versus Albumin Fluid Evaluation (SAFE) Study, a doubleblind multi-center randomized controlled trial, essentially found no difference in mortality between the colloid and crystalloid groups [43]. However, in subgroup analysis the authors discovered slightly higher mortality (RR 1.36) among trauma patients who received $4 \%$ albumin as compared to NS. Overall though the findings from this study are difficult to interpret, as the albumin group received significantly higher amounts of non-study fluid [normal saline and packed red blood cells (pRBCs)] than albumin during the first four hospital days.

Despite these conflicting results, many clinicians believe albumin, especially the highly concentrated form, is a viable option for resuscitation of trauma patients, particularly for its anti-inflammatory properties. In ex vivo studies, $25 \%$ albumin has been shown to inhibit neutrophil adhesion to endothelial cells, an important step in the process of polymorphonuclear (PMN) cell translocation [44]. This process has also been shown to reduce the amount of neutrophil sequestration and activation that ultimately culminates in a pro-inflammatory state leading to end-organ injury [22]. As with other colloids, albumin is advantageous over crystalloids due to its small size and weight. Available in $100 \mathrm{cc}$ bottles, it is easily transported to the scene of injury for pre-hospital resuscitation. These characteristics, combined with its proven ability to expand the intravascular space, have made it the ideal fluid for resuscitation in combat by the Committee for Tactical Combat Casualty Care [45].

Dextran is a synthetic colloid that is often combined with $7.5 \%$ saline for use as a hypertonic resuscitative agent. By increasing osmotic pressure, hypertonic-saline dextran (HSD) has been shown to be superior to other colloids in increasing intravascular volume [32]. Multiple randomized controlled trials have been performed to test whether this benefit leads to an improvement in patient outcome. The trials have offered conflicting results based on the population studied [46]. In summary, non-TBI patients with active bleeding may benefit, while those with severe head injuries may do worse. These findings make it difficult to recommend the use of this agent in the multitrauma patient with a TBI.

With so many options and conflicting data it is difficult to determine whether colloids are superior to crystalloids during initial resuscitation. Two recent Cochrane Review analyses were unable to definitively determine whether one colloid was superior to another [42], or even superior to crystalloids [41] in the treatment of critically ill patients. Recently the CRISTAL study sought to answer the question once and for all. It was a large multicenter randomized controlled trial that compared crystalloids (LR, NS, $3 \%$ NS) versus colloids of all types (gelatins, dextran, hydroxyethyl starch, albumin) and strengths in the resuscitation of hypotensive ICU patients. The investigators found that although the colloid group received significantly less fluids and required less ventilator and hemodynamic assistance, there was no difference in hospital or 30-day mortality. When the patients were followed out to 90 days, however, a slight survival advantage was detected. Although encouraging, this study is not applicable to the trauma population, as the majority (55\%) of the patients' underlying problem was sepsis, with trauma accounting for only $5 \%$. Until a large randomized study of trauma patients is performed, the choice of fluids remains unclear.

\section{Blood Products}

From the initial ATLS guidelines that emphasized aggressive transfusion of crystalloids at the expense of blood products, the paradigm of fluid management has completely changed its priorities with an emphasis on early correction of coagulopathy and avoidance of over-transfusion. Thanks to widespread acceptance of continuously evolving practice patterns, such as massive transfusion protocols and DCR, patients are receiving life-saving blood products in a timely and judicious manner. The development of new diagnostic modalities, such as TEG, has allowed for a more individualized-approach to resuscitation. Initial studies describing the use of rapid-thrombelastography (r-TEG) at the point of care have been promising; numerous studies have demonstrated r-TEG can accurately diagnose coagulopathies in a fraction of the time required for standard coagulation profiles [47, 48]. Others have advocated its use as an adjunct in determining adequate resuscitation [49], and demonstrated improved 
survival as compared to standard massive transfusion protocols [50]. The relative benefits of the test have not been sufficient to justify its expense for many small nonacademic centers, so its current availability is limited to larger tertiary centers. In the following section we offer one transfusion protocol for the traumatically injured.

Current transfusion protocols have evolved from the days of giving two units of pRBCs and waiting for a response. Due in no small part to the combat injuries sustained in Iraq and Afghanistan, the United States military has contributed significantly to the concepts of massive transfusion and balanced resuscitation. Over the course of the conflicts military physicians continuously modified their practice patterns; massive transfusions accounted for nearly $50 \%$ of all transfusions in 2011 [51]. Fresh whole blood was utilized in situations when the demand for blood components outnumbered its pre-packaged supply [51-53]. They found that nearly one-third of their patients were coagulopathic on admission, and by increasing the ratio of both FFP and platelets to $\mathrm{pRBC}$, they were able to decrease mortality rates despite increasing injury severity scores [54]. These concepts have been adopted by civilian centers and have ignited a mission to find the optimal resuscitative ratio.

Massive transfusions have long been an important component of the care for the traumatically injured, but it has only been within the last decade that trauma centers have implemented formal protocols governing its use. The idea behind the mass transfusion protocol (MTP) is to quickly identify patients that will likely require more than four units of $\mathrm{pRBC}$ and have the blood products thawed and ready for use. The results thus far have been mixed. The studies have uniformly documented a significant decrease in blood availability time, however, this has not always translated into a reduction in component use or mortality [55-57]. One investigator discovered an interesting trend when reviewing his institution's outcomes before and after the implementation of a MTP. He found that although there was no difference in mortality among patients who received a MT, survival was doubled in patients who received a "sub-MT", i.e., greater than six but less than 10 units of pRBCs [58]. Further investigation revealed that these patients received significantly more FFP and platelets in the first $6 \mathrm{~h}$, at higher ratios, following institution of the MTP. This study lends evidence in support of early correction of coagulopathy, one of the primary goals of DCR.

Fresh frozen plasma is obtained via apheresis of whole blood and frozen within $8 \mathrm{~h}$ [59]. It contains all the clotting factors, fibrinogen, proteins $\mathrm{C}$ and $\mathrm{S}$, and albumin. It is available in 250 and $500 \mathrm{cc}$ bags that must be thawed and used within $24 \mathrm{~h}$ or it becomes classified as frozen plasma, which has been shown to contain significantly less clotting factors and a diminished ability to restore intravascular volume [60]. FFP has also been shown to be significantly less immunogenic than pRBCs [61, 62], and decreases vascular leakage through stabilization of the endothelial membrane [60].

Multiple studies have sought to determine whether FFP's benefits in the laboratory and the deployed setting are translatable to civilian trauma, and if so, to determine the optimal transfusion ratio. Holcomb et al. [63] was one of the first to address this problem. In his retrospective analysis of multiple level 1 trauma centers he found that a FFP:pRBC ratio greater than 1:2 was associated with significantly lower thirty-day mortality in patients who were severely injured (mean ISS 32) and received a mass transfusion. Other investigators have corroborated these findings with even higher FFP:pRBC ratios [64-66], while another was able to demonstrate an early survival benefit with a balanced approach regardless of admission coagulopathy [67]. When investigators looked at trauma patients who received a sub-massive transfusion the results became more complicated. Some investigators identified early high ratio transfusion as an independent predictor of survival, both early and late, without an increase in the incidence of transfusion-related complications such sepsis, MODS, and venous thromboembolism [68•]. Others have published results suggesting the practice is not beneficial, and even harmful, to patients in this population [69, 70]. To add clarity to these conflicting results, the Cochrane group has launched its own review, with results expected soon [71]. Based on available data, the goal for massive transfusion patients is to transfuse to a FFP:pRBC ratio of nearly $1: 1$, while in patients receiving less than 10 units of $\mathrm{pRBC} / 24 \mathrm{~h}$ a more conservative approach of 1:2 should be pursued.

Platelets are another blood component that has been heavily investigated in the recent literature. Although a dedicated analysis failed to demonstrate a correlation between admission platelet count and mortality, an association was discovered between the count and early transfusion requirements [72]. Encouraged by additional evidence that platelets' contribution to the coagulopathy of trauma may be more qualitative than quantitative [9, 73], investigators set out to determine if the benefit of the high transfusion ratios seen with FFP also hold true for platelets. Several multicenter analysis have demonstrated a survival advantage, at $24 \mathrm{~h}$ as well as 30 days, in massively transfusion patients who received a platelet:pRBC ratio $>1: 1.5$ [63, 64, 74]. This advantage was additive when combined with a high FFP:pRBC ratio, specifically among patients with exsanguinating truncal hemorrhage. The investigators also noted improvements in ventilator-free days as well as ICU and hospital length of stays. Others have found no difference in mortality after adjusting for confounders $[57,70]$. The push for a balanced platelet transfusion 
protocol has not been born out in the literature. An optimal approach would be to transfuse platelets at a ratio near 1:3.

Historically pRBCs have been the primary blood component utilized by trauma providers attempting to actively replace the blood loss of the hemorrhaging patient. To produce a $300 \mathrm{cc}$ unit of $\mathrm{pRBCs}$, fresh whole blood must undergo extensive processing. Immediately upon extraction the blood must be mixed with a citrate-phosphatedextrose solution to prevent coagulation [75]. It is then centrifuged down and the buffy coat is removed. These procedures extend the shelf-life of blood to 42 days [76]. Leukoreduction is an additional step where white blood cells are removed by specialized filters, decreasing the overall burden to less than $0.1 \%$ [77].

Transfusion of blood products, however, is not without complications. The processes of preparation and storage of blood products have been associated with the development of transfusion-related complications such as transfusionrelated lung injury (TRALI), the systemic inflammatory response syndrome (SIRS), and multi-organ failure (MOF) $[78,79]$. Data has linked these complications to neutrophil priming particles such as microparticles (MP's) and lysophosphatidylcholine (lyso-PC's) that have been shown to accumulate over time [61, 80]. Aged blood has also been shown to be less efficient in coagulation, as measured by the activated coagulation time [81]. All of these factors may contribute to its increased mortality when used in the hemorrhaging trauma patient [82]. Pre-storage procedures such as leukoreduction and washing have been shown to decrease the inflammatory response, making the transfusion of aged pRBCs a viable option for these patients [77, 83].

Through the various mechanisms described above, as well as its proven role in $\mathrm{T}$ cell suppression [84], the number of units of pRBCs transfused has been shown to be an independent risk factor for mortality in this population [77, 85]. This underscores the importance of determining the optimal transfusion threshold. Several investigators have attempted to answer this question. Ryan et al. retrospectively reviewed admission hematocrit (HCT) with the need for transfusion and vasopressor support among trauma patients requiring emergency surgery. The authors found that in this cohort of patients admission HCT as low as $37 \%$ was predictive of the need for additional hemodynamic support [86]. Interestingly, they found that traditional markers of shock, including pulse and respiratory rate, were not predictors for necessitating further hemodynamic support. A study by Long et al. examined postoperative HCT levels and survival among trauma patients who received a massive transfusion. They found that patients who were transfused to physiologic levels (HCT 29-39\%) postoperatively had better short term survival compared to those patients transfused to supraphysiologic levels, $>39 \%$ [87]. These studies are limited by their retrospective nature, finite population (patients who required emergency surgery), as well as their lack of long-term outcomes, however, they provide a basis for further prospective analysis for trauma transfusion thresholds. The transfusion of $\mathrm{pRBCs}$ is not without significant risk of adverse events such as TRALI and MODS, and this risk appears to be proportional to the amount and the age of the blood transfused. However, one should not withhold transfusion in the appropriate patient. The combination of indices, such as vital signs, lactate, $\mathrm{pH}$, and base deficit, along with clinical judgment is the best approach to transfusing a hemorrhaging trauma patient.

Two relatively new hemostatic adjuncts, recombinant Factor VIIa (rVIIa) and Tranexamic Acid (TXA), have been used more frequently in recent years. Studies published from the U.S. military conflicts in Iraq and Afghanistan have added to the increased application of these products in the trauma population. Retrospective data on rVIIa from massively transfused combat casualty patients demonstrated both short and long-term survival, decreased transfusion requirements, and similar rates of inflammatory or thromboembolic complications in patients who received rVIIa compared to those who did not receive the drug $[88,89]$. The CONTROL trial was acivilian phase III prospective, randomized, placebo-controlled multicenter trial evaluating rVIIa in both blunt and penetrating trauma [90•]. Over 500 patients were enrolled from 150 hospitals across the world. Unfortunately, the study was stopped early after preliminary data demonstrated the futility in meeting the primary endpoint of decreased mortality, as the observed mortality was significantly lower than expected. From the analyzed data collected, however, the subgroup of blunt trauma patients receiving rVIIa received fewer units of pRBCs and FFP than the subgroup of blunt trauma patients receiving the placebo drug. The authors also found that there was no difference in adverse events between the rVIIa and placebo groups. With the available published literature, use of rVIIa should be limited to the ongoing hemorrhaging trauma patients receiving a massive transfusion.

TXA is an antifibrinolytic that binds to plasminogen and prevents its conversion to plasmin [91]. Interest in it arose as a potential adjunct to correcting the coagulopathy of trauma after years of data from cardiac surgery demonstrated decreased fibrinolysis with decreased blood loss and subsequent transfusion requirements, associated with TXA's use [92, 93]. The Clinical Randomization of an Antifibrinolytic in Significant Hemorrhage 2 trial (CRASH-2) was the first large multi-center, randomized, prospective placebo-controlled trial that evaluated TXA's use in actively hemorrhaging trauma patients [94•]. Over 20,000 patients were enrolled from 270 hospitals 
worldwide. The primary endpoint was in-hospital 30-day mortality. There was a significant reduction in all-cause mortality in the TXA group ( $p=0.0035)$, as well as death due to hemorrhage $(p=0.0077)$ and no difference in vascular occlusive events $(p=0.096)$, although these benefits were only realized if TXA was administered within $3 \mathrm{~h}$ of injury. However, there was no difference in transfusion rates between the TXA and placebo groups.

The Military Application of Tranexamic Acid in Trauma Emergency Resuscitation (MATTERs) study was a retrospective comparison of transfusion requirements, thromboembolic events, and mortality between combat injured who received TXA and at least one unit of pRBC's versus those injured who received at least one transfusion and no TXA [95••]. Similar to the CRASH-2 trial, patients receiving TXA had a mortality rate that was significantly lower than those who did not receive TXA, despite the fact that the TXA group was more severely injured, coagulopathic, and hemodynamically unstable. This survival advantage was more pronounced in the subgroup of patients receiving a massive transfusion. The investigators also discovered significantly higher rates of thromboembolic events and blood product usage in the TXA group, contradictory to the findings in the CRASH-2 trial, which were attributed to the higher severity of injury in the combat wounded.

The Cochrane investigators recently performed of a review of the two randomized clinical trials that compared TXA versus placebo in the treatment of traumatic injuries and concluded that the mortality benefit from uncontrolled hemorrhage is extremely time dependent [96]. If the drug is given within $3 \mathrm{~h}$ of injury the relative risk reduction is $21 \%$, whereas administration after that time period incurs a relative risk increase of $44 \%$. Based on the available data in the trauma literature, TXA should be considered as a hemostatic agent in the massively transfused patient if given within $3 \mathrm{~h}$ of injury. Administration outside that window incurs an increase in thromboembolic events without a survival benefit.

\section{Conclusion}

DCR has revolutionized how we approach the hemorrhaging trauma patient. It is based on the principles of judicious crystalloid use, tolerance of permissive hypotension, and balanced transfusion of blood products. When presented with an actively bleeding patient, resuscitation with no more than $2 \mathrm{~L}$ of warmed isotonic crystalloid is an appropriate first step. The complications related to overresuscitation are well established. However, the maximal threshold for total volume of crystalloid resuscitation has not yet been elucidated in the literature, therefore a definitive recommendation cannot be given. Instead, physiologic parameters such as pulse rate, blood pressure, hemoglobin level, lactate, $\mathrm{pH}$, and base deficit combined with sound clinical judgment should guide one's resuscitation. If the patient fails to respond to the initial bolus, one should identify the source of bleeding and begin transfusion of blood products in a roughly 1:1:1 ratio. The decision to activate a massive transfusion protocol should be made early. Once activated, consider administering adjuncts such as TXA or rVIIa early in the resuscitative process.

Acknowledgments This article was reviewed by Dr. Vincent Degos of Hôpital Robert Debré in Paris, France.

\section{Compliance with Ethics Guidelines}

Conflict of Interest Matthew J. Bradley and Vincente S. Nelson declare that they have no conflict of interest.

Human and Animal Rights and Informed Consent This article does not contain any studies with human or animal subjects performed by any of the authors.

\section{References}

Papers of particular interest, published recently, have been highlighted as:

- Of importance

•- Of major importance

1. Sauaia A, Moore FA, Moser EE, Brennan KS, Read RA, Pons PT. Epidemiology of trauma deaths: a reassessment. J Trauma. 1995;38(2):185-93.

2. Navarro S, Montmany S, Rebasa P, Colilles C, Pallisera A. Impact of ATLS training on preventable and potentially preventable deaths. World J Surg. 2014;38:2273-8.

3. Cripps MW, Kutcher ME, Daley A, McCreery RC, Greenberg MD, Cachola LM, Redick BJ, Nelson MF, Cohen MJ. Cause and timing of death in massively transfused trauma patients. J Trauma Acute Care Surg. 2013;75(2):S255-62.

4. Watts DD, Trask A, Soeken K, Perdue P, Dols S, Kaufmann C. Hypothermic coagulopathy in trauma: effect of varying levels of hypothermia on enzyme speed, platelet function, and fibrinolytic activity. J Trauma. 1997;55(5):846-54.

5. Reynolds BR, Forsythe RM, Harbrecht BG, Cuschieri J, Minei JP, Maier RV, Moore EE, Billiar TR, Peitzman AB, Sperry JL, The Inflammation and the Host Response to Injury Investigators, Pittsburgh, Pennsylvania. Hypothermia in massive transfusion: Have we been paying enough attention to it? Journal of Trauma and Acute Care Surgery. 2012;73(2):486-91.

6. Brohi K, Singh J, Heron M. Acute traumatic coagulopathy. J Trauma. 2003;54:1127-30.

7. Brohi K, Cohen MJ, Ganter MT, Matthay MA, Mackersie RC, Pittet J-F. Acute traumatic coagulopathy: initiated by hypoperfusion modulated through the protein c pathway? Ann Surg. 2007;245:812-8.

8. MacLeod JBA, McCoy CC, Hillyer CD, Shaz BH. Early trauma induced coagulopathy (ETIC): Prevalence across the injury spectrum. Injruy. 2014;45:910-5. 
9. Johansson PI, Sorensen AM, Perner A, Welling KL, Wanscher M, Larsen CF, SR Ostrowski. High sCD40L levels early after trauma are associated with enhanced shock, sympathoadrenal activation, tissue and endothelial damage, coagulopathy and mortality. J Thromb Haemost. 2012;10(2):207-16.

10. Enderson BL, Robinson R, Maull KI. Fibrinolysis in multisystem trauma patients. J Trauma. 1991;31(9):1240-6.

11. Committee on Trauma, American College of Surgeons. ATLS Advanced Trauma Life Support for doctors. 9th ed. Chicago: American College of Surgeons; 2012.

12. Duchesne JC, Heaney J, Guidry C, McSwain N Jr, Meade P, Cohen M, Schreiber M, Inaba K, Skiada D, Demetriades D, Holcomb J, Wade C, Cotton B. Diluting the benefits of hemostatic resuscitation: a multi-institutional analysis. J Trauma Acute Care Surg. 2013;75:76-82.

13. Rotondo MF, McGonigal MD, Phillips GR III, Fruchterman TM, Kauder DR, Latenser BA, Angood PA. 'Damage control': an approach for improved survival in exsanguinating penetrating abdominal injury. J Trauma. 1993;35(3):375-82.

14. Holcomb JB, Jenkins D, Rhee P, Johannigman J, Mahoney P, Mehta S, Darrin Cox E, Gehrke MJ, Beilman GJ, Schreiber M, Flaherty SF, Grathwohl KW, Spinella PC, Perkins JG, Beekley AC, Neil M, McMullin R, Park MS, Gonzalez EA, Wade CE, Dubick MA, William Schwab C, Moore FA, Champion HR, Hoyt DB, Hess JR. Damage control resuscitation: directly addressing the early coagulopathy of trauma. J Trauma. 2007;62:307-10.

15. Palm K, Apodaca A, Spencer D, Costanzo G, Bailey J, Blackbourne LH, Spott MA, Eastridge BJ. Evaluation of military trauma system practices related to damage-control resuscitation. J Trauma Acute Care Surg. 2012;73:S459-64.

16. Cotton BA, Reddy N, Hatch QM, LeFebvre E, Wade CE, Kozar RA, Gill BS, Albarado R, McNutt MK, Holcomb JB. Damage control resuscitation is associated with a reduction in resuscitation volumes and improvement in survival in 390 damage control laparotomy patients. Ann Surg. 2011;254(4):598-605.

17. Joseph B, Zangbar B, Pandit V, Vercruysse G, Aziz H, Kulvatunyou N, Wynne J, O'Keeffe T, Tang A, Friese RS, Rhee P. The conjoint effect of reduced crystalloid administration and decreased damage-control laparotomy use in the development of abdominal compartment syndrome. J Trauma Acute Care Surg. 2014;76:457-61.

18. Schnüriger B, Inaba K, Wu T, Eberle BM, Belzberg H, Demetriades $\mathrm{D}$. Crystalloids after primary colon resection and anastomosis at initial trauma laparotomy: excessive volumes are associated with anastomotic leakage. J Trauma Acute Care Surg. 2011;70:603-10.

19. Bradley M, Dhanda A, Rodriguez C, Lauerman M, DuBose J, Scalea T, Stein D. Damage control resuscitation protocol and the management of open abdomens in trauma patients. Unpublished. 2014.

20. Bradley MJ, Scalea TM, Holcomb JB, Shrestha B, Okoye O, Inaba K, Bee TK, Fabian TC, Whelan J, Ivatury RR. Independent predictors of enteroatmospheric fistula and abdominal sepsis after damage control laparotomy: results of a prospective, observational AAST study. Unpublished. 2014.

21. Harvin JA, Mims MM, Duchesne JC, Cox CS Jr, Wade CE, Holcomb JB, Cotton BA. Chasing 100\%: The use of hypertonic saline to improve early, primary fascial closure after damage control laparotomy. J Trauma Acute Care Surg. 2013;74:426-32.

22. Alam HB, Stanton K, Koustova E, Burris D, Rich N, Rhee P. Effect of different resuscitation strategies on neutrophil activation in a swine model of hemorrhagic shock. Resuscitation. 2005;60:91-9.

23. Lazaridis C, Neyens R, Bodle J, DeSantis SM. High-osmolarity saline in neurocritical care: systematic review and meta-analysis. Crit Care Med. 2013;41:1353-60.
24. Morrison CA, Carrick MM, Norman MA, Scott BG, Welsh FJ, Tsai P, Liscum KR, Wall MJ Jr, Mattox KL. Hypotensive resuscitation strategy reduces transfusion requirements and severe postoperative coagulopathy in trauma patients with hemorrhagic shock: preliminary results of a randomized controlled trial. J Trauma Acute Care Surg. 2011;70:652-63.

25. Dutton RP, Mackenzie CF, Scalea TM. Hypotensive resuscitation during active hemorrhage: impact on in-hospital mortality. J Trauma. 2002;52:1141-6.

26. Chesnut RM, et al. The role of secondary brain injury in determining outcome from severe head injury. J Trauma. 1993; 34(2):216-22.

27. Marmarou A, Anderson RL, Ward JD, et al. Impact of ICP instability and hypotension on outcome in patients with severe head trauma. J Neurosurg. 1991;75:S59-66.

28. Clifton GL, et al. Fluid thresholds and outcome from severe brain injury. Crit Care Med. 2002;30(4):739-45.

29. Nordstrom $\mathrm{CH}$, et al. Assessment of the lower limit for cerebral perfusion pressure in severe head injuries by bedside monitoring of regional energy metabolism. Anesthesiology. 2003;98(4): 809-14.

30. Contant CF, et al. Adult respiratory distress syndrome: a complication of induced hypertension after severe head injury. J Neurosurg. 2001;95(4):560-8.

31. Robertson CS, et al. Prevention of secondary ischemic insults after severe head injury. Crit Care Med. 1999;27(10):2086-95.

32. Dubniks Maris, Persson J, Grände P-O. Comparison of the plasma volume-expanding effects of $6 \%$ dextran $70,5 \%$ albumin, and $6 \%$ HES 130/0.4 after hemorrhage in the guinea pig. J Trauma. 2009;67(6):1200-4.

33. Zarychanski R, Abou-Setta AM, Turgeon AF, Houston BL, McIntyre L, Marshall JC, Fergusson DA. Association of hydroxyethyl starch administration with mortality and acute kidney injury in critically ill patients requiring volume resuscitation: a systematic review and meta-analysis. JAMA. 2013;309(7):678-88.

34. Chrissy G, Gleeson E, Simms ER, Stuke L, Meade P, McSwain NE Jr, Duchesne JC. Initial assessment on the impact of crystalloids versus colloids during damage control resuscitation. J Surg Res. 2013;185:294-9.

35. Ogilvie MP, Pereira BM, McKenney MG, McMahon PJ, Manning RJ, Namias N, Livingstone AS, Schulman CI, Proctor KG. First report on safety and efficacy of hetastarch solution for initial fluid resuscitation at a level 1 trauma center. J Am Coll Surg. 2010;210(5):870-80.

36. Lissauer ME, Chi A, Kramer ME, Scalea TM, Johnson SB. Association of $6 \%$ hetastarch resuscitation with adverse outcomes in critically ill trauma patients. Am J Surg. 2011;202:53-8.

37. Jacob M, Chappell D, Conzen P, Wikes MM, Becker BF, Rehm M. Small-volume resuscitation with hyperoncotic albumin: a systematic review of randomized clinical trials. Crit Care Med. 2008;12(R34):1-13.

38. Boldt J, Muller M, Mentges D, Papsdorf M, Hempelmann G. Volume therapy in the critically ill: is there a difference? Intensive Care Med. 1998;24(1):28-36.

39. Boldt J, Muller M, Heesen M, Neumann K, Hempelmann GG. Influence of different volume therapies and pentoxifylline infusion on circulating soluble adhesion molecules in critically ill patients. Crit Care Med. 1996;24(3):385-91.

40. Boldt J, Heesen M, Müller M, Pabsdorf M, Hempelmann G. The effects of albumin versus hydroxyethyl starch solution on cardiorespiratory and circulatory variables in critically ill patients. Anesth Analg. 1996;83:254-61.

41. Perel P, Roberts I, Ker K. Colloids versus crystalloids for fluid resuscitation in critically ill patients (review). Cochrane Database Syst Rev. 2013;2:1-73. 
42. Bunn F, Trivedi D. Colloid solutions for fluid resuscitation (review). Cochrane Database Syst Rev. 2012;7:1-82.

43. TSS Investigators. A comparison of albumin and saline for fluid resuscitation in the intensive care unit. JAMA. 2004;350(22): 2247-56.

44. Powers KA, Kapus A, Khadaroo RG, Papia G, Rotstein OD. 25\% albumin modulates adhesive interactions between neutrophils and the endothelium following shock/resuscitation. Surgery. 2002; 132(2):391-8.

45. Rhee P. Albumin. J Trauma. 2011;70(5):S22-4.

46. Bulger EM. $7.5 \%$ saline and $7.5 \%$ saline/6\% dextran for hypovolemic shock. J Trauma. 2011;70(5):S27-9.

47. Jeger V, Zimmermann H, Exadaktylos AK. Can rapidTEG accelerate the search for coagulopathies in the patient with multiple injuries? J Trauma. 2009;66(4):1253-7.

48. Kaufmann CR, Dwyer KM, Crews JD, Dols SJ, Trask AL. Usefulness of thrombelastography in assessment of trauma patient coagulation. J Trauma. 1997;42(4):716-22.

49. Holcomb JB, Minei KM, Scerbo ML, Radwan ZA, Wade CE, Kozar RA, Gill BS, Albarado R, McNutt MK, Khan S, Adams PR, McCarthy JJ, Cotton BA. Admission rapid thrombelastography can replace conventional coagulation tests in the emergency department: experience with 1974 consecutive trauma patients. Ann Surg. 2012;256(3):476-86.

50. Tapia NM, Chang A, Norman M, Welsh F, Scott B, Wall MJ, Mattox KL, Suliburk J. TEG-guided resuscitation is superior to standardized MTP resuscitation in massively transfused penetrating trauma patients. J Trauma Acute Care Surg. 2013;74(2): 378-86.

51. Pidcoke HF, Aden JK, Mora AG, Borgman MA, Spinella PC, Dubick MA, Blackbourne LH, Cap AP. Ten-year analysis of transfusion in Operation Iraqi Freedom and Operation Enduring Freedom: Increased plasma and platelet use correlates with improved survival. J Trauma Acute Care Surg. 2012;73: S445-52.

52. Nessen SC, Cronk D, Craig RM, Berséus O, Ellison R, Remick K, Seery J, Shah A, Spinella PC. Fresh whole blood use by forward surgical teams in Afghanistan is associated with improved survival compared to component therapy without platelets. Transfusion. 2013;53:S1107-38.

53. Chan CM, Shorr AF, Perkins JG. Factors associated with acute lung injury in combat casualties receiving massive blood transfusions: a retrospective analysis. J Crtic Care. 2012;27:419-27.

54. Spinella PC, Dunne J, Beilman GJ, O'Connell RJ, Borgman MA, Cap AP, Rentas F. Constant challenges and evolution of US military transfusion medicine and blood operations in combat. Transfusion. 2012;52:1146-53.

55. Riskin DJ, Tsai TC, Riskin L, Hernandez-Boussard T, Purtill M, Maggio PM, Spain DA, Brundage SI. Massive transfusion protocols: the role of aggressive resuscitation versus product ratio in mortality reduction. J Am Coll Surg. 2009;209:198-205.

56. O'Keeffe T, Refaai M, Tchorz K, Forestner JE, Sarode R. A massive transfusion protocol to decrease blood component use and costs. Arch Surg. 2008;143(7):686-91.

57. Lustenberger T, Frischknecht A, Brüesch M, Keel MJB. Blood component ratios in massively transfused, blunt trauma patients-a time-dependent covariate analysis. J Trauma. 2011;71:1144-51.

58. Kautza BC, Cohen MJ, Cuschieri J, Minei JP, Brackenridge SC, Maier RV, Harbrecht BG, Moore EE, Billiar TR, Peitzman AB, Sperry JL. The Inflammation and the Host Response to Injury Investigators, Pittsburgh, Pennsylvania. Changes in massive transfusion over time: an early shift in the right direction. J Trauma. 2011;72(1):106-11.

59. Nascimento B, Callum J, Rubenfeld G, Neto JB, Lin Y, Rizoli S. Clinical Review: fresh frozen plasma in massive bleedings- more questions than answers. Crit Care Med. 2010;14(1):18.
60. Pati S, Matijevic N, Doursout M-F, Ko T, Cao Y, Deng X, Kozar RA, Hartwell E, Conyers J, Holcomb JB. Protective effects of fresh frozen plasma on vascular endothelial permeability, coagulation, and resuscitation after hemorrhagic shock are time dependent and diminish between days 0 and 5 after thaw. J Trauma. 2010;69:S55-63.

61. Silliman CC, Boshkov LK, Mehdizadehkashi Z, Elzi DJ, Dickey WO, Podlosky L, Clarke G, Ambruso DR. Transfusion-related acute lung injury: epidemiology and a prospective analysis of etiologic factors. Blood. 2003;101(2):454-62.

62. Makley AT, Goodman MD, Belizaire RM, Friend LA, Johannigman JA, Dorlac WC, Lentsch AB, Pritts TA. Damage control resuscitation decreases systemic inflammation after hemorrhage. J Surg Res. 2012;175(2):e75-82.

63. Holcomb JB, Wade CE, Michalek JE, Chisholm GB, Zarzabal LA, Schreiber MA, Gonzalez EA, Pomper GJ, Perkins JG, Spinella PC, Williams KL, Park MS. Increased plasma and platelet to red blood cell ratios improves outcome in 466 massively transfused civilian trauma patients. Ann Surg. 2008;248(4):447-58.

64. Brown JB, Cohen MJ, Minei JP, Maier RV, West MA, Billiar TR, Peitzman AB, Moore EE, Cushieri J, Sperry JL, The Inflammation and the Host Response to Injury Investigators. Debunking the survival bias myth: Characterization of mortality during the initial 24 hours for patients requiring massive transfusion. J Trauma Acute Care Surg. 2012;73(2):358-64.

65. Teixeira PG, Inaba K, Shulman I, Salim A, Demetriades D, Brown C, Browder T, Green D, Rhee P. Impact of plasma transfusion in massively transfused trauma patients. J Trauma. 2009;66:693-7.

66. Guidry C, DellaVope J, Simms E, Heaney JB, Guice J, McSwain $\mathrm{N}$ Jr, Meade P, Duchesne JC. Impact of inverse ratios on patients with exsanguinating vascular injuries: should more be the new paradigm? J Trauma Acute Care Surg. 2012;74(2):403-10.

67. Brown LM, Aro SO, Cohen MJ, The Trauma Outcomes Group. A high fresh frozen plasma: packed red blood cell transfusion ratio decreases mortality in all massively transfused trauma patients regardless of admission international normalized ratio. J Trauma. 2011;71(2):S358-63.

68. - Wafaisade A, Maegele M, Lefering R, Braun M, Peiniger S, Neugebauer E, Bouillon B, The Trauma Registry of DGU. High plasma to red blood cell ratios are associated with lower mortality rates in patients receiving multiple transfusion $(4<$ red blood cell units $<10)$ during acute trauma resuscitation. J Trauma. 2011;70(1):81-89. Retrospective analysis that demonstrated a mortality benefit (both early and late) in patients who received a balanced transfusion, independent of the number of pRBC's transfused.

69. Inaba K, Branco BC, Rhee P, Blackbourne LH, Holcomb JB, Teixeira PGR, Shulman I, Nelson J, Demetriades D. Impact of plasma transfusion in trauma patients who do not require massive transfusion. J Am Coll Surg. 2010;210:957-65.

70. Sambasivan CN, Kunio NR, Nair PV, Zink KA, Michalek JE, Holcomb JB, Schreiber MA, The Trauma Outcomes Group. High ratios of plasma and platelets to packed red blood cells do not affect mortality in nonmassively transfused patients. J Trauma. 2011;71(2):S329-36.

71. Haas B, Gomez D, Steel A, Nathens A. Ratio of units of red blood cells to fresh frozen plasma for severely injured patients undergoing massive transfusion. Cochrane Database Syst Rev. 2012;3:1-8.

72. Brown LM, Call MS, Knudson MM, Cohen MJ. The Trauma Outcomes Group. Admission platelet count on mortality and transfusion in severely injured trauma patients. J Trauma. 2011;71(2):S337-42.

73. Kutcher ME, Redick BJ, McCreery RC, Crane IM, Greenberg MD, Cachola LM, Nelson MF, Cohen MJ. Characterization of 
platelet dysfunction after trauma. J Trauma Acute Care Surg. 2012;73(1):13-9.

74. Holcomb JB, Zarzabal LA, Michalek JE, Kozar RA, Spinella PC, Perkins JG, Matijevic N, Dong J-F, Pati S, Wade CE, The Trauma Outcomes Group. Increased platelet:RBC ratios are associated with improved survival after massive transfusion. J Trauma. 2011;71(2):S318-28.

75. Burger P, Korsten H, Verhoeven AJ, de Korte D, van Bruggen R. Collection and storage of red blood cells with anticoagulant and additive solution with a physiologic $\mathrm{pH}$. Transfusion. 2012;52(6): 1245-52.

76. Kiraly LN, Underwood S, Differding JA, Schreiber MA. Transfusion of aged packed red blood cells results in decreased tissue oxygenation in critically injured trauma patients. J Trauma. 2009;67(1):29-32.

77. Phelan HA, Eastman AL, Aldy K, Carroll EA, Nakonezny PA, Jan T, Howard JL, Chen Y, Friese RS, Minei JP. Prestorage leukoreduction abrogates the detrimental effect of aging on packed red cells transfused after trauma: a prospective cohort study. Am J Surg. 2012;203:198-204.

78. Khan H, Belsher J, Yilmaz M, Afessa B, Winters JL, Moore SB, Hubmayr RD, Gajic O. Fresh-frozen plasma and platelet transfusions are associated with development of acute lung injury in critically Ill medical patients. Chest. 2007;131(5):1308-14.

79. Sharpe JP, Weinberg JA, Magnotti LJ, Fabian TC, Croce MA. Does plasma transfusion portend pulmonary dysfunction? A tale of two ratios. J Trauma Acute Care Surg. 2013;75(1):32-6.

80. Belizaire RM, Prakash PS, Richter JR, Robinson BR, Edwards MJ, Caldwell CC, Lentsch AB, Pritts TA. Microparticles from stored red blood cells activate neutrophils and cause lung injury after hemorrhage and resuscitation. J Am Coll Surg. 2012;214: 648-57.

81. Aucar JA, Sheth M. The storage lesion of packed red blood cells affects coagulation. J Surg. 2012;152:697-703.

82. Spinella PC, Carroll CL, Staff I, Gross R, McQuay J, Keibel L, Wade CE, Holcomb JB. Duration of red blood cell storage is associated with increased incidence of deep vein thrombosis and in hospital mortality in patients with traumatic injuries. Crit Care Med. 2009;13(5):R151.

83. Belizaire RM, Makley AT, Campion EM, Sonnier DI, Goodman MD, Dorlac WC, Friend LA, Lentsch AB, Pritts TA. Resuscitation with washed aged packed red blood cell units decreases the proinflammatory response in mice after hemorrhage. J Trauma Acute Care Surg. 2012;73(2):S128-33.

84. Long K, Meier C, Ward M, Williams D, Woodward J, Bernard A. Immunologic profiles of red blood cells using in vitro models of transfusion. J Surg Res. 2013;184:567-71.

85. Dunne JR, Malone DL, Tracy JK, Napolitano LM. Allogenic blood transfusion in the first 24 hours after trauma is associated with increased systemic inflammatory response syndrome (SIRS) and death. Surg Infect. 2004;54:395-404.
86. Ryan ML, Thorson CM, Otero CA, Vu T, Schulman CI, Livingstone AS, Proctor KG. Initial hematocrit in trauma: a paradigm shift? J Trauma. 2012;72(1):54-60.

87. Long K, Heaney JB, Simms ER, McSwain NE, Duchesne JC. When enough is enough: impact of packed red blood cells in massive transfusion outcomes. Am Surg. 2013;79(8):810-4.

88. Spinella PC, Perkins JG, McLaughlin DF, Niles SE, Grathwohl KW, Beekley AC, Salinas J, Mehta S, Wade CE, Holcomb JB. The effect of recombinant activated factor VII on mortality in combat-related casualties with severe trauma and massive transfusion. J Trauma. 2008;64:286-94.

89. Perkins JG, Schreiber M, Wade CE, Holcomb JB. Early versus late recombinant factor VIIa in combat trauma patients requiring massive transfusion. J Trauma. 2007;62(5):1095-9, discussion $1099-101$.

90. - Hauser CJ, Boffard K, Dutton R, Bernard GR, Croce MA, Holcomb JB, Leppaniemi A, Parr M, Vincent J-L, Tortella BJ, Dimsits J, Bouillon B, for the CONTROL Study Group. Results of the CONTROL trial: efficacy and safety of recombinant activated factor VII in the management of refractory traumatic hemorrhage. J Trauma. 2010;69(3):489-500. The use of rVII, however, was associated with decreased transfusion requirements without an increase in thromboembolic events.

91. Rappold JF, Pusateri AE. Tranexamic acid in remote damage control resuscitation. Transfusion. 2013;53:96S-9S.

92. Casati V, Gerli C, Franco A, Torri G, D’Angelo A, Benussi S, Alfieri O. Tranexamic acid in off-pump coronary surgery: a preliminary, randomized, double-blind, placebo- controlled study. Ann Thorac Surg. 2001;72:470-5.

93. Casati V, Della Valle P, Benussi S, Franco A, Gerli C, Baili P, Alfieri O, D'Angelo A. Effects of tranexamic acid on postoperative bleeding and related hematochemical variables in coronary surgery: comparison between on-pump and off-pump techniques. J Throcic Carviovasc Surg. 2004;128(1):83-91.

94. - The CRASH-2 Collaborators, Effects of tranexamic acid on death, vascular occlusive events, and blood transfusion in trauma patients with significant haemorrhage (CRASH-2): a randomised, placebo-controlled trial. Lancet. 2010;376: 23-32. Phase III Trial that demonstrated a survival advantage in the group who received TXA as compared to the control group.

95. • Morrison JJ, Dubose JJ, Rasmussen TE, Midwinter MJ. Military application of tranexamic acid in trauma emergency resuscitation (MATTERs) study. Arch Surg. 2012;147(2):113-119. Retrospective analysis of combat wounded which demonstrated improved 30 day survival in patients who received TXA as compared to those who did not. The improvement was greatest among patients who received a massive transfusion.

96. Roberts I, Shakur H, Ker K, Coats T, On behalf of the CRASH-2 Trial collaborators. Antifibrinolytic drugs for acute traumatic injury (review). Cochrane Database Syst Rev. 2012;2:1-23. 